\title{
Preface to the Legacy Edition
}

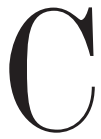

redential inflation is the rise in educational requirements for jobs as a rising proportion of the population attains more advanced degrees. The value of a given educational certificate or diploma declines as more people have them. In the United States, high school diplomas (i.e., twelve-year secondary school) were comparatively rare before 1940; now high school degrees are so commonplace that their job value is worthless. University attendance is now over 60 percent of the youth cohort and is on the way to the same fate as the high school degree. The main thing that inflated degrees are worth is to plough them back into the educational market, seeking still higher degrees. This in principle is an endless process; it could very well reach the situation of the Chinese mandarin class during the Ming and Xing dynasties, when students continued sitting for exams into their thirties and forties-only now this would affect the vast majority of the population instead of a small elite. Different countries have gone through educational inflation at different rates, but from the second half of the twentieth century onward, all of them have followed this path.

Educational degrees are a type of currency of social respectability, which are traded in for access to jobs. Like any currency, it inflates prices (or reduces purchasing power) when autonomously driven increases in monetary supply chase a limited stock of goods, in this case chasing a diminishing pool of middle-class jobs. Educational 
inflation builds on itself; from the point of view of the individual degree-seeker, the best response to its declining value is to get even more education.

Although this is the primary mechanism of educational expansion, it is bolstered by prevailing technocratic ideology. Rising technical requirements of jobs drive out unskilled labor, the argument goes, and today's high-skilled jobs demand steadily increasing levels of education. Forty years ago, in The Credential Society (1979), I assembled evidence to show that technological change is not the driving force in rising credential requirements. The content of education is not predominantly set by technological demand; most technological skills_including the most advanced ones-are learned on the job or through informal networks, and the bureaucratic organization of education at best tries to standardize skills innovated elsewhere. In updated research on credential inflation vis-à-vis technological change, I have seen nothing that overturns my conclusions published in 1979. The outburst of information technology that transformed the postindustrial economy was led by people such as Steve Jobs, who dropped out of college to seize opportunities to create new products and new business enterprises; and this has been the pattern with the entrepreneurs who created Facebook, Google, Tesla, and others by exploiting the technological edge. This happens because the technological edge is found out there in the networks of people working in the next-to-the-last-minute edge. School systems standardize what has already happened; that is the reason dropouts who seize the opportunities for innovation directly have greater success than those who follow the bureaucratic path through the step by step of required years in school systems and the hierarchies of already full-grown organizational employers.

It is true that a small proportion of jobs benefit from scientific and technical education, but that is not what is driving the massive expansion of education. It is implausible that in the future the entire labor force will be scientists or skilled technicians. Indeed, the largest area of job growth in rich countries has been low-skilled service jobs for which it is cheaper to hire human labor than to automate. 
Educational credential inflation expands on false premises-the ideology that more education will produce more equality of opportunity, more high-tech economic performance, and more good jobs. Social class mobility in the United States has been stagnant since the mid-twentieth century, unaffected by the huge increase in levels of education over that period. High-tech innovation has largely come out of on-the-job experience multiplied into new combinations by alert entrepreneurs. The proportion of good jobs has declined as the middle class has been hollowed out, and working-class jobs exist mainly in the poorly paid service sector.

But the inflationary expansion of the educational sector does provide a potential solution to a profound problem now becoming apparent in the advanced economies of the world: technological displacement of the middle class, as computerization and the development of artificial intelligence threaten to eliminate nonmanual jobs. In twenty or thirty years, capitalist societies may collapse because business organizations will have eliminated most paid workers, thus leaving no one who can afford to buy capitalist products. Credential inflation helps mitigate this problem by keeping more people out of the labor force. If students receive financial subsidies, either directly or in the form of low-cost (and ultimately un-repaid) loans, they act as hidden transfer payments. In places like the United States where the welfare state is ideologically unpopular, the mythology of education supports a hidden welfare state. Add the millions of teachers in elementary, secondary, and higher education, and their administrative staffs; the hidden Keynesianism of educational inflation may be said virtually to keep the capitalist economy afloat. There is the danger, of course, of technologizing education, that is, displacing teachers with computers or hiring a few human teachers to broadcast their classes and eliminating all other teachers. If this were to proceed to the extreme, education would be less of an escape from technological displacement. Barring this, is continued educational expansion a likely route to a Keynesian solution to technological displacement?

Education is a major cost of government, and this tends to limit future expansion. With higher costs, there are pressures to privatize, 
shifting the burden of funding to students or parents. But this, too, faces a limit as the middle class is economically squeezed. For decades, the cost of college and professional schools has grown far faster than the rate of inflation in the economy. Education administrators could get away with increasingly higher prices because of credential inflation, which increases the number of applicants competing for a chance at the most prestigious degrees. Student loans put off the reckoning, but at some point it becomes economically infeasible to sustain the inflationary spiral inside the credential-producing sector. Here we see a difference between inflation of a monetary currency and inflation of diplomas. Printing more money is easy to do and just cheapens the currency; but the equivalent of printing degrees is costly and becomes increasingly expensive as more students crowd the competition.

An expanding educational system driven by credential inflation reaches a potential crisis point within the educational system itself. This is not necessarily final. One can envision a series of such plateaus, stopping and restarting as our secular faith in salvation through education goes through disillusionment and revival.

This particularly affects those of us who are university teachers. Even though the educational system is based on false premises, I felt badly about publishing my critique of educational inflation because most of my colleagues depend on it for jobs. After finishing my 1979 book, I quit the university and became a full-time writer. But teaching was more remunerative, and after a few years I came back. Everything has to draw its resources from somewhere, and that is true for the existence of sociology itself. Ironically, sociology exposes the false premises that ideologically protect its own material base. Would mass political opinion continue to support education if it did not have utopian beliefs about it? Within another twenty or thirty years, we shall see.

Randall Collins

Professor of Sociology Emeritus,

University of Pennsylvania 